\title{
TNF system in eutopic endometrium from women with endometriosis
}

\author{
María Angélica Boric ${ }^{1}$, Marisa Torres ${ }^{1}$, Claudio Pinto ${ }^{1}$, Maricela Pino ${ }^{1}$, Paulina Hidalgo ${ }^{1}$, \\ Fernando Gabler $^{2,3}$, Ariel Fuentes ${ }^{1,3}$, María Cecilia Johnson ${ }^{1}$ \\ ${ }^{1}$ Institute of Maternal and Child Research, Faculty of Medicine, University of Chile, Santiago, Chile \\ ${ }^{2}$ Department of Pathology, Faculty of Medicine, University of Chile, Santiago, Chile \\ ${ }^{3}$ San Borja-Arriarán Clinical Hospital, Santiago, Chile \\ Email: cjohnson@med.uchile.cl
}

Received 1 February 2013; revised 28 February 2013; accepted 8 March 2013

\section{ABSTRACT}

The role of the tumor necrosis factor (TNF) system in endometriosis is not completely clear and therefore was the focus of this study. In eutopic endometria obtained from women with $(n=41)$ and without (controls; $n=34$ ) endometriosis during laparoscopy, the subcellular location and the percentages for TNF, TNFR1, TNFR2 and CD45 positive-cells were determined (immunohistochemistry); the protein concentration (ELISA) of the soluble receptors (sTNFR1 and STNFR2) were measured in 4h-explants culture media and the TNF concentration was performed in ex vivo endometrial homogenates. The TNF, TNFR1 and TNFR2 mRNAs were analyzed by real-time PCR. In control endometria, TNF, TNFR1 and sTNFR1 proteins increased during the late secretory phase. In endometriosis endometria, the protein highest level of TNFR1 was reached during the early and the mid secretory phases and of sTNFR1 concentration during the proliferative phase; however, during the late secretory phase, both TNFR1 and sTNFR1 protein levels were reduced compared to the control endometria ( $<0.05$ ). TNFR2 was scarcely immunodetected in some CD45-positive stromal cells. The TNFand CD45-positive cell percentages, the TNF and sTNFR2 concentrations, and TNF and TNFR2 mRNAs were similar in control and endometriosis endometria. Although TNFR1 mRNA was highly expressed, no significant differences were found between control and endometriosis endometria. In summary, this study establishes that TNF and TNFR1 protein expressions and the sTNFR concentrations in eutopic endometria from women with and without endometriosis are dependent on the menstrual cycle. The differences on the TNFR1 and sTNFR1 protein pattern between both groups, mainly during the mid and late secretory phases may play a role in the lower im- plantation rates observed in women with endometriosis, and also could be related to the altered cell death, which favor the augmented cell viability facilitating the characteristic endometrial implantation and growth outside the uterus in this disease.

Keywords: Endometriosis; Eutopic Endometrium; TNF; STNFR1; sTNFR2

\section{INTRODUCTION}

In the human endometrium, inflammatory events normally occur during the menstrual cycle and involve an environment rich in cytokines produced by endometrial stromal and epithelial cells and invasive macrophages [1]. Endometriosis, pregnancy loss and failures in embryo implantation have been associated with the dysregulation of cytokines.

Endometriosis is an inflammatory disease characterized by extra-uterine viable endometrial tissue and strongly associated with pelvic pain and infertility. Its etiology remains unclear although the retrograde menstruation/transplantation theory is widely accepted and the augmented cell survival of eutopic endometrium during the late secretory phase and mense, described in this disease, allows the implantation and development outside the uterus by not clarified mechanisms [2-4]. These developing endometriotic lesions on peritoneal or ovarian surfaces also include an increased number of activated macrophages and lymphocytes that secrete numerous cytokines, producing a local inflammatory reaction that, over time, develops into chronic inflammation $[5,6]$.

Tumor necrosis factor alpha (TNF) plays a crucial role in inflammation, angiogenesis, cell proliferation and cell death. It is widely expressed in several tissues associated with reproduction, including endometrium [7], where participates in several physiological inflammatory events, such as embryo implantation and menstruation [8-10]. 
This cytokine can be either a 26-kDa membrane-anchored trimeric precursor or a $17-\mathrm{kDa}$ soluble factor cleaved by TNF-converting enzyme (TACE or ADAM17) that modulates the effects of TNF [11,12]. The actions of TNF are mediated by two membrane receptors, TNFR1 and TNFR2 $[13,14]$, which can also be cleaved by proteases to yield soluble proteins (sTNFR) that retain the capacity to bind TNF $[14,15]$.

Although TNF and both TNFRs have been studied throughout the menstrual cycle, their expression patterns in the human endometrium have not been well established $[7,9,16,17]$. In endometriosis, the concentrations of TNF, sTNFR1 and sTNFR2 in the peritoneal fluid are significantly elevated, in concordance with the high numbers of active macrophages and lymphocytes, which are both cytokine producers $[5,18]$.

Here we present the protein localization and/or concentration of TNF, TNFR1 and TNFR2 in eutopic endometria throughout the menstrual cycle from women with and without endometriosis. In addition, the concentrations of sTNFR1 and sTNFR2 in the culture media of endometrial explants were studied.

\section{MATERIALS AND METHODS}

\subsection{Subjects}

Eutopic endometria were obtained with a Pipelle suction curette from women (BMI $\leq 26 \mathrm{~kg} / \mathrm{m}^{2}$ ) undergoing laparoscopy for endometriosis (endometriosis, $\mathrm{n}=41$; $33.6 \pm 4.9$ years) or for tubal sterilization (controls, $\mathrm{n}=$ $34 ; 35.5 \pm 7.1$ years). The women had no hormonal treatment for at least 3 months before surgery. Each patient signed a written informed consent, and the Institutional Committee Boards approved this study.

After washing the tissues with ice-cold phosphate buffered saline (PBS), a portion was placed in formalin/ PBS (pH 7.2 - 7.4) for histological evaluation and immunohistochemistry, and the rest was cut into slices for explant cultures, or frozen at $-80^{\circ} \mathrm{C}$ for RNA and protein preparations. The endometria were classified according to Noyes criteria in proliferative (days $6-14,10$ controls and 9 endometriosis), and secretory (days $15-28,24$ controls and 32 endometriosis) phases. The secretory phase was subdivided in early: days $15-18$ (8 controls and 13 endometriosis), mid: days $19-23$ (8 controls and 9 endometriosis) and late: days $24-28$ ( 8 controls and 10 endometriosis).

\subsection{Explant Cultures}

Slices (20 - $30 \mathrm{mg}$ wet-weight) were incubated in $1 \mathrm{~mL}$ defined medium (DMEM [Sigma Co., St. Louis, MO, USA], $0.1 \% \mathrm{w} / \mathrm{v}$ bovine serum albumin [BSA; Sigma], Glutamax [Invitrogen, Carlsbad, CA, USA], $25 \mathrm{mmol} / \mathrm{L}$ HEPES, $100 \mathrm{IU} / \mathrm{mL}$ penicillin and $5 \mathrm{mg} / \mathrm{mL}$ streptomycin [Sigma]) for $4 \mathrm{~h}$ at $37^{\circ} \mathrm{C}$ in $5 \% \mathrm{CO}_{2} /$ air in humidified atmosphere. After incubation, the tissues were frozen at $-80^{\circ} \mathrm{C}$ for the measurement of TNF and the media maintained at $-20^{\circ} \mathrm{C}$ for the measurements of the sTNFR 1 and sTNFR2 concentrations.

\subsection{RNA Preparation, cDNA Synthesis, Real-Time PCR}

Total RNA was extracted from frozen endometrial tissue with Trizol (Invitrogen), treated with DNAse (Ambion Inc., Austin, TX, USA), and $2 \mu \mathrm{g}$ were used for cDNA synthesis as described in Pino et al. (2009) [19]. Primer sequences for real-time PCR, designed using Primer Express software version 3.0 (Applied Biosystems, Foster City, CA, USA) were: TNF 5'-CAG GTC TAC TTT GGG ATC ATT GC-3' (forward) and 5'-GCG TTT GGG AAG GTT GGA-3' (reverse); TNFR1 5'-GCT CCA AAT GCC GAA AGG A-3' (forward) and 5'-CCG GTC CAC TGT GCA AGA A-3' (reverse); TNFR2 5'-AGG CCC CAC CAG ATC TGT AA-3' (forward) and 5'-GCA TCC ATG CTT GCA TTC C-3' (reverse); and GAPDH 5'-AGC CGC ATC TTC TTT TGC-3' (forward) and 5'-AAT GAA GGG GTC ATT GAT GG-3' (reverse). The reaction volume was $10 \mu \mathrm{L}$ containing $1 \times$ Fast $\mathrm{SYBR}^{\circledR}$ Green PCR Master Mix (Applied Biosystems), $300 \mathrm{nM}$ (TNF and TNFR1) or $600 \mathrm{nM}$ (TNFR2 and GAPDH) of each specific human primer and $1 \mu \mathrm{L}$ cDNA (corresponding to $40 \mathrm{ng}$ of total RNA) used as template in a StepOne Plus Real-Time PCR System (Applied Biosystems). The relative RNA levels were calculated using delta-delta cycle threshold method (Applied Biosystems) where GAPDH was used as endogenous control and a pool of six control proliferative endometria was used as calibrator sample.

\subsection{TNF, TNFR1, TNFR2 and CD45 Immunohistochemistry}

Immunohistochemical staining was performed on formalin-fixed, paraffin-embedded endometrial sections as described in Johnson et al. (2005) [4] using antibodies against TNF (1:200; MAB1096, Chemicon International, Inc., Temecula, CA, USA), TNFR1 (1:100, rabbit polyclonal, Santa Cruz Biotechnology, Santa Cruz, CA, USA), TNFR2 (1:75, goat polyclonal and 1:75, mouse monoclonal raised against to $\mathrm{C}$-terminal aminoacids, Santa Cruz) and CD45 (1:50; rabbit polyclonal, Dako Corp., Carpinteria, CA, USA). All slides were treated with $10 \mathrm{mmol} / \mathrm{L}$ citrate buffer $(\mathrm{pH}$ 6.0), quenched, blocked and incubated with the primary antibodies at $37^{\circ} \mathrm{C}$ for $1 \mathrm{~h}$. The immunodetection was performed using the streptavidin-biotin peroxidase system (LSAB-2, Dako), diaminobenzidine as a chromogen and hematoxylin for counterstaining. The slides incubated with the TNFR2 antibody raised in goat were incubated with anti 
goat secondary antibody HRP conjugated (1:800, Santa Cruz) instead of the anti mouse and anti rabbit secondary antibodies included in the LSAB-2 kit. For TNFR2 positive control was used basal endometrium and for negative control, the primary antibody was replaced by $1 \%$ BSA in PBS. The immunohistochemistry was evaluated as the percentage of positively staining cells by the examination of at least 1000 cells from each sample by three blinded observers.

\subsection{TNF, sTNFR1 and sTNFR2 Concentrations}

The concentration of TNF was measured in 100- $\mu \mathrm{g}$ cytoplasmic protein (Ponce et al., 2009) [20], and those of sTNFR1 and sTNFR2 in 200- $\mu$ l endometrial explants culture media (R\&D Systems Inc., Minneapolis, MN, USA) on a microplate reader (BioRad model 680) at 450 $\mathrm{nm}$ and $540 \mathrm{~nm}$ (wavelength correction). The assay sensitivities were $1.6 \mathrm{pg} / \mathrm{mL}$ for TNF, $0.77 \mathrm{pg} / \mathrm{mL}$ for sTNFR1 and $0.6 \mathrm{pg} / \mathrm{mL}$ for sTNFR2. The intra- and inter-assay variation coefficients were $5.3 \%$ and $6.8 \%$ for TNF, $4.4 \%$ and $3.9 \%$ for sTNFR 1 , and $2.6 \%$, and $3.5 \%$ for sTNFR2, respectively.

\subsection{Statistical Analysis}

The results are expressed as the means \pm SEM of the experiment number indicated in the Table and Figure Legends. The data were analysed by a Student's t-test or one-way ANOVA followed by Tukey's multiple comparison test. Statistical significance was defined as $\mathrm{p}<$ 0.05 . The patients' ages are expressed as the means \pm SD. GraphPad Prism 4.0 software was used to conduct statistical analysis.

\section{RESULTS}

\subsection{TNF, TNFR1, TNFR2 and CD45 Immunohistochemistry}

In the control endometria, a wide range (from absent to a strong brown color) of TNF staining was observed in the surface of epithelial and stromal cells during the proliferative phase, which became more intense and homogeneous during the secretory phase; in endometriosis, moderate to strong staining in both cell compartments throughout the menstrual cycle was found (Figure 1(A), (B), (C) and (D)). Weak TNFR1 staining was located mainly in the epithelial cells of both endometrial groups (Figure 1(E), (F), (G) and (H)). Both antibodies against TNFR2 scarcely detected some positive cells in the stromal compartment in endometria from women with and without endometriosis (Figure 1(I), (J), (M) and (N)). Similarly, the leukocyte common antigen CD45 was detected on the surface of some cells located in the stromal cell compartment of control and endometriosis endo- metria (Figure 1(K) and (O)). The similar position of the brown staining for TNFR2 in some CD45-positive cells suggests the same cell type.

The percentage of TNF-positive cells increased from the proliferative to secretory phases in epithelial cell compartment of control and endometriosis samples (Table 1). Although the TNF-positive cell percentage was higher in endometriosis cells than control cells this difference was not significant.

In the control endometrium, the highest percentage of TNFR1-positive cells was detected in both epithelial and stromal cells during the late secretory phase; in contrast, in endometriosis endometria, this percentage was the lowest, being $60 \%$ and $70 \%$ smaller than control in epithelial and stromal cells, respectively. Moreover, in patients with endometriosis the percentage of positive-cells was $260 \%$ and $220 \%$ higher in epithelial cells during the early and mid secretory phases and $270 \%$ in stromal cells during the mid-secretory phase compared to the control (Table 1). Because of the scarce number of TNFR2positive cells found with both antibodies used, the semiquantitation was not performed.

In the endometria from women without (control) and with endometriosis, the percentage of CD45-positive stromal cells increased $100 \%$ and $220 \%$ during the mid and the late secretory phases, respectively, compared to the proliferative phase; in the epithelial cell compartment, the positive cells were always less than 3\% (Table 1).

\subsection{TNF, sTNFR1 and sTNFR2 Concentrations}

In control and endometriosis endometrial homogenates, TNF was scarcely detected and no difference was found in its concentration during the proliferative and the secretory phases (Figure 2(a)).

In the culture media after $4 \mathrm{hr}$ incubation of control endometrial explants, the sTNFR1 concentration was higher during the late secretory phase than the early secretory phase $(14.5 \pm 0.6 \mathrm{pg} / \mathrm{mL}$ and $9.8 \pm 1 \mathrm{pg} / \mathrm{mL}$, respectively). In contrast, in the endometriosis culture media, the highest sTNFR1 concentration value was during the proliferative phase. When both groups of endometrial culture media were compared, sTNFR1 concentration from endometriosis was higher during the proliferative phase (endometriosis: $20.8 \pm 3.6 \mathrm{pg} / \mathrm{mL}$ and control: 11.9 $\pm 1.7 \mathrm{pg} / \mathrm{mL}$ ) but lower during the late secretory phase (endometriosis: $9.6 \pm 1.5 \mathrm{pg} / \mathrm{mL}$ and control: $14.5 \pm 0.6$ $\mathrm{pg} / \mathrm{mL}$ ), similarly to immunohistochemical results (Figure 2(b)).

The sTNFR2 concentration strongly decreased from the proliferative to the secretory phases in both the control and endometriosis endometrial culture media, with no differences between them (Figure 2(c)). The concentration of sTNFR2 was lower than that of sTNFR1 in the culture media. 


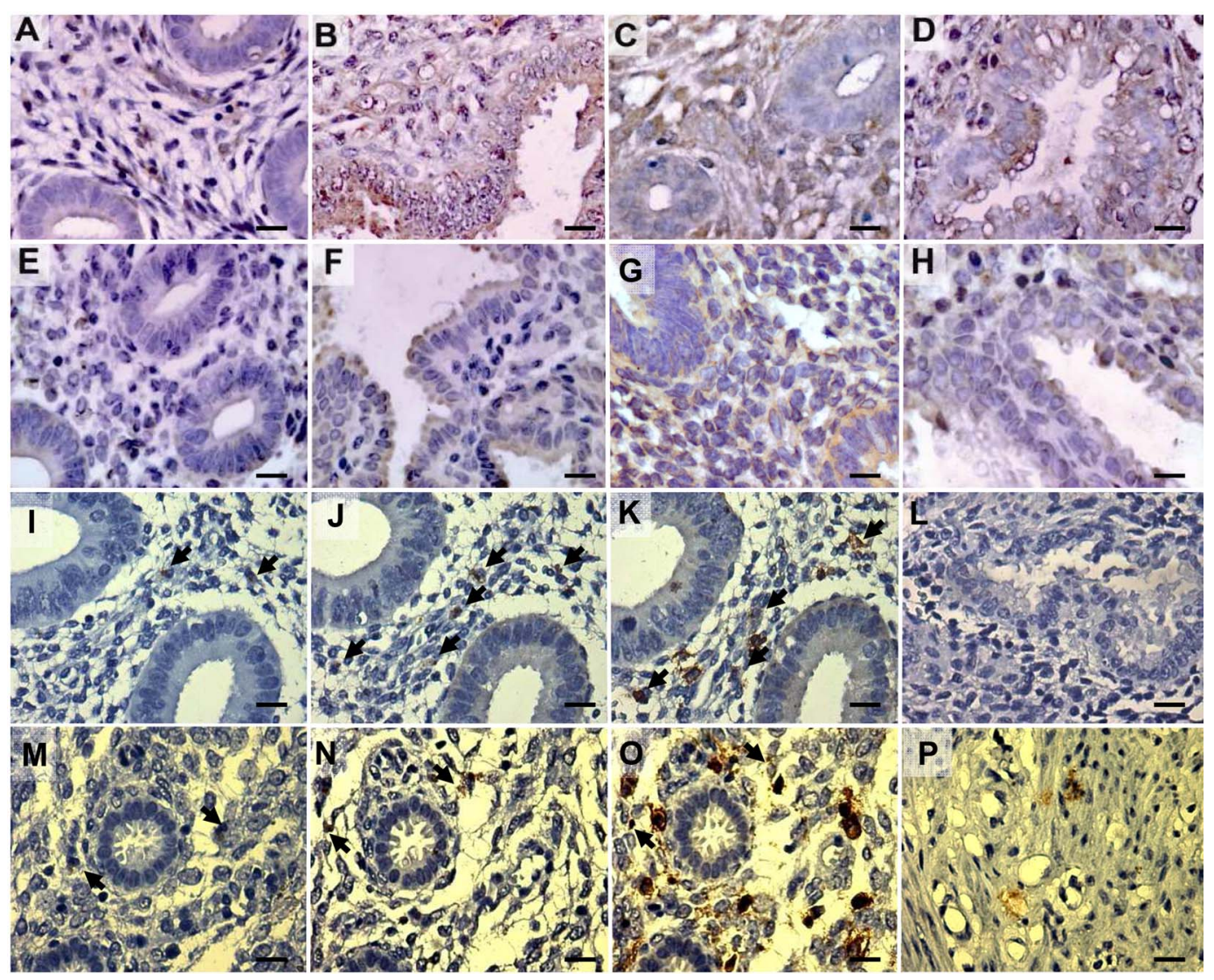

Figure 1. Immunohistochemical location of TNF, TNFR1, TNFR2 and CD45 in eutopic endometria from women without (control) and with endometriosis. Representative human endometria explants in paraffin wax sections from control (A, B, E, F, I-L) and endometriosis (C, D, G, H, M-P) women with positive immunostaining for TNF (A-D), TNFR1 (E-H), TNFR2 (I, J, M, N and P [I and M antibody raised in goat; J, N and $\mathrm{P}$ antibody raised in mouse]) and $\mathrm{CD} 45(\mathrm{~K}$ and $\mathrm{O})$ during the proliferative $(\mathrm{A}, \mathrm{C}, \mathrm{E}, \mathrm{G}, \mathrm{I}-\mathrm{K})$ and secretory phase (B, D, F, H, L-P). Positive cytoplasmic staining was detected in both stroma and epithelia for TNF and TNFR1 and mainly in the stroma for TNFR2 and CD45. Basal endometrium was used as positive control for TNFR2 (P). Negative control (L). Black arrows indicate the same position in serial endometrial sections. Magnification in all panels is $400 \times$. Scale bars represent $30 \mu \mathrm{m}$.

Table 1. TNF, TNFR1 and CD45 positive cells in human eutopic endometria during the menstrual cycle.

\begin{tabular}{|c|c|c|c|c|c|c|c|c|c|}
\hline \multirow[b]{3}{*}{ Protein } & \multirow[b]{3}{*}{ Cell Type } & \multicolumn{4}{|c|}{ Control } & \multicolumn{4}{|c|}{ Endometriosis } \\
\hline & & \multicolumn{5}{|c|}{ Secretory } & \multicolumn{3}{|c|}{ Secretory } \\
\hline & & $\begin{array}{c}\text { Proliferative } \\
(\%)\end{array}$ & $\begin{array}{l}\text { Early } \\
(\%)\end{array}$ & $\begin{array}{l}\text { Mid } \\
(\%)\end{array}$ & $\begin{array}{l}\text { Late } \\
(\%)\end{array}$ & $\begin{array}{c}\text { Proliferative } \\
(\%)\end{array}$ & $\begin{array}{l}\text { Early } \\
(\%)\end{array}$ & $\begin{array}{l}\text { Mid } \\
(\%)\end{array}$ & $\begin{array}{l}\text { Late } \\
(\%)\end{array}$ \\
\hline \multirow{2}{*}{$\mathrm{TNF}$} & EEC & $66.5 \pm 11$ & $85.1 \pm 13$ & $93.0 \pm 4^{\#}$ & $90.0 \pm 9.7^{\#}$ & $86.8 \pm 6$ & $92.1 \pm 3$ & $98.8 \pm 1^{\#}$ & $97.6 \pm 1$ \\
\hline & $\mathrm{ESC}$ & $75.1 \pm 12$ & $84.0 \pm 16$ & $88.5 \pm 6$ & $88.4 \pm 8$ & $89.4 \pm 5$ & $95.4 \pm 2$ & $97.2 \pm 1$ & $94.4 \pm 2$ \\
\hline \multirow{2}{*}{ TNFR1 } & EEC & $51.2 \pm 11$ & $21.2 \pm 11$ & $21.9 \pm 12$ & $66.7 \pm 11^{\&}$ & $88.2 \pm 5$ & $76.5 \pm 12^{*}$ & $70.8 \pm 14^{*}$ & $27.4 \pm 9^{* \# \varepsilon^{\circ}}$ \\
\hline & $\mathrm{ESC}$ & $32.5 \pm 11$ & $12.3 \pm 5$ & $6.6 \pm 4$ & $49.1 \pm 14^{\circ}$ & $45.6 \pm 10$ & $22.1 \pm 9$ & $23.7 \pm 8^{*}$ & $14.4 \pm 5^{*}$ \\
\hline \multirow{2}{*}{$\mathrm{CD} 45$} & EEC & $1.3 \pm 1$ & $2.0 \pm 1$ & $1.9 \pm 1$ & $2.8 \pm 1$ & $1.5 \pm 1.0$ & $1.0 \pm 1$ & $2.5 \pm 1$ & $2.7 \pm 1$ \\
\hline & ESC & $11.7 \pm 2$ & $22.4 \pm 3.0$ & $23.0 \pm 3^{\#}$ & $37.4 \pm 4^{\#}$ & $15.8 \pm 2$ & $15.5 \pm 3$ & $29.1 \pm 4^{\#}$ & $51.1 \pm 5^{\#}$ \\
\hline
\end{tabular}

Positive cell percentage was evaluated in endometrial sections obtained from women without (control) and with endometriosis at proliferative phase (TNF: 10 and 6 samples, TNFR1: 8 and 6 samples, and CD45: 4 and 4 samples); early secretory (TNF: 6 and 8 samples, TNFR1: 8 and 8 samples, and CD45: 4 and 10 samples); mid secretory (TNF: 7 and 6 samples, TNFR1: 4 and 7 samples, and CD45: 6 and 6 samples) and late secretory (TNF: 6 and 6 samples, TNFR1: 8 and 10 samples, and CD45: 8 and 5 samples), respectively. ${ }^{*} \mathrm{p}<0.05$ versus control endometrium; ${ }^{*} \mathrm{p}<0.05$ versus proliferative phase; ${ }^{\&} \mathrm{p}<0.05$ versus early secretory phase; ${ }^{\circ} \mathrm{p}<0.05$ versus mid secretory phase. EEC: endometrial epithelial cells; ESC: endometrial stromal cells. 


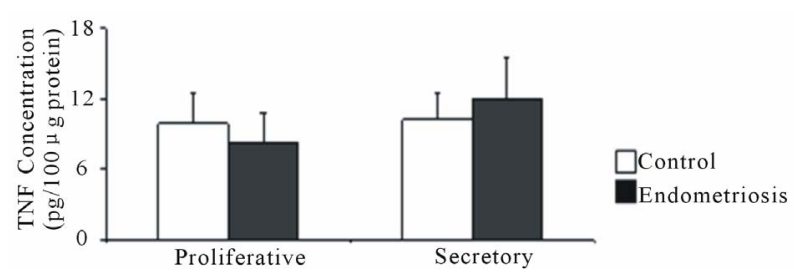

(a)

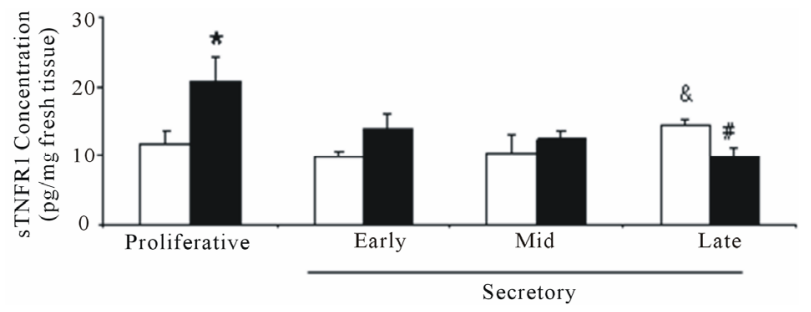

(b)

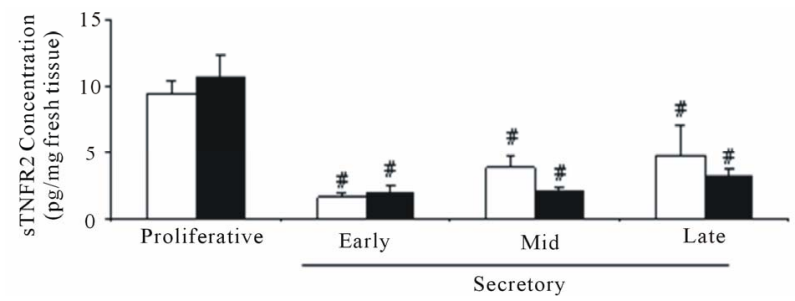

(c)

Figure 2. Concentration of TNF, sTNFR1 and sTNFR2 in eutopic endometrium throughout the menstrual cycle. (a) TNF was measured in $100 \mu \mathrm{g}$ of endometrial homogenate prepared from women without (control) and with endometriosis: proliferative (4 and 3 samples) and secretory (4 and 5 samples) phases, respectively; (b) sTNFR1 and (c) sTNFR2 measured in $200 \mu \mathrm{L}$ culture media of endometrial explants from women without (control) and with endometriosis: proliferative phase ( 7 and 6 samples) and early (6 and 8 samples), mid- (7 and 7 samples) and late (7 and 9 samples) secretory phases, respectively. Values are the mean \pm SEM of samples indicated in each stage of the menstrual cycle. ${ }^{*} \mathrm{p}<0.05$ versus control endometrium; ${ }^{*} \mathrm{p}<0.05$ versus proliferative phase; ${ }^{\&} \mathrm{p}<0.05$ versus early secretory phase.

\subsection{TNF, TNFR1 and TNFR2 mRNA Expression}

The mRNAs of TNF (Figure 3(a)), TNFR1 (Figure 3(b)) and TNFR2 (Figure 3(c)) were expressed in control and endometriosis endometria; the predominant receptor was TNFR1 in both endometrial groups. Only in control endometria, the levels of the three mRNAs increased at mid and/or late secretory phases. Although the TNFR1 mRNA expression was higher in endometriosis endometria than control endometria, no significant differences were detected between both endometrial groups.

\section{DISCUSSION}

To establish the potential role of TNF and its receptors in endometriosis, we studied their protein location and expression in eutopic endometrium throughout the menstrual cycle.

We describe the expression of TNF, TNFR1 and TNFR2 mRNAs and the concentrations of sTNFR1 and

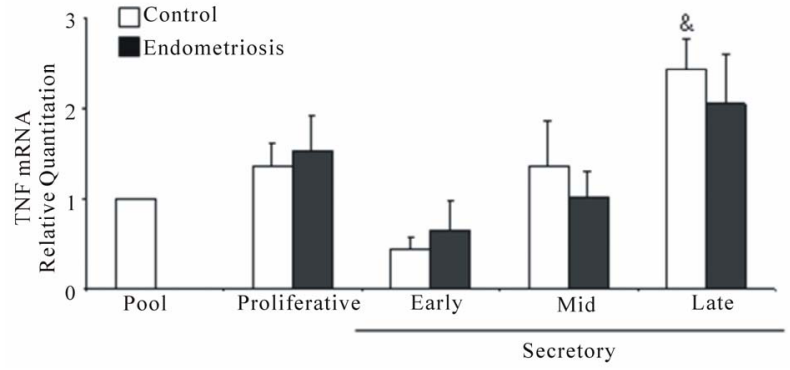

(a)

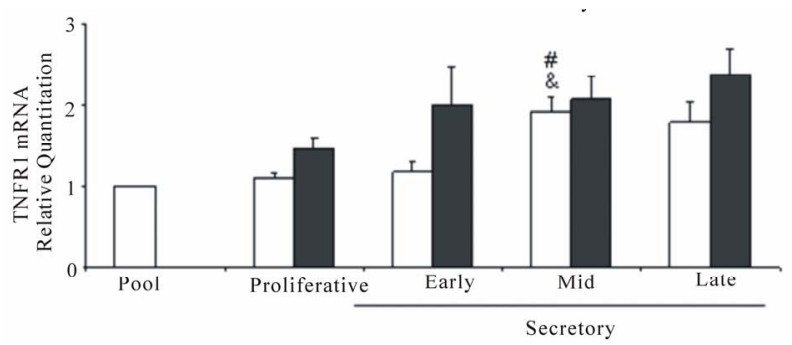

(b)

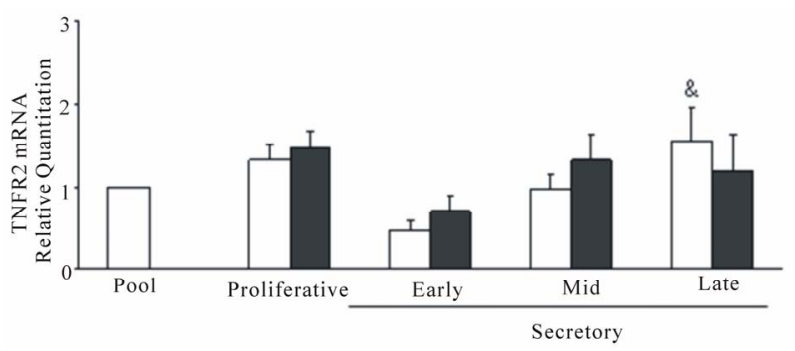

(c)

Figure 3. TNF (a), TNFR1 (b) and TNFR2 (c) mRNA expression in eutopic endometria throughout the menstrual cycle. Total RNA was extracted from endometria obtained from women without ( $n=26$, controls) and with $(\mathrm{n}=33)$ endometriosis and the mRNA expression was analyzed in duplicates by real-time PCR as described in Materials and Methods. The relative RNA levels were calculated using delta-delta cycle threshold method (Applied Biosystems) where GAPDH was used as endogenous control and a pool of control proliferative endometria (Pool) was used as calibrator sample. Values are the mean \pm SEM of at least 6 samples in each stage of the menstrual cycle. $\#$ p $<0.05$ versus proliferative phase; ${ }^{\&} \mathrm{p}<0.05$ versus early secretory phase.

sTNFR2 in eutopic endometrium from women with and without endometriosis, which are dependent on the menstrual cycle; also, we found differences in the protein pattern of ex vivo TNFR1 and sTNFR1 between the studied groups.

In accordance with other authors [16,17], the TNF protein was located in epithelial and stromal cells throughout the menstrual cycle. The TNF action is known to be mediated through the membrane receptors TNFR1 and TNFR2 expressed in reproductive tissues such as pregnant uterus and placenta $[7,8]$, although TNFR2 protein has been detected mainly in immune cells infiltrated in endometrial decidua [21], similarly to our results where its protein was found in some cells, probably infiltrate leukocytes, in the stromal compartment. 
The endometrial TNF and TNFR1 protein patterns found in the present study revealed a dependence on the menstrual cycle suggesting an ovarian steroid hormones regulation, results supported by ex vivo and in vitro endometrial reports $[9,10,16,17]$. In the present study, the highest levels of TNF and TNFR1 occurred during the late secretory phase in control endometria, stage related with apoptosis, the physiological process involved in the menstrual shedding in a non-conceptional cycle. On the contrary, in the eutopic endometrium from women with endometriosis, the altered TNFR1 pattern may be affecting the implantation window as consequence to the augmented TNF response trough TNFR1 during the mid secretory phase. In addition, the almost absent apoptosis in the eutopic and ectopic endometria coincided with TNFR1 protein reduction during the late secretory phase, allowing the survival and growth of the menstrual debris outside the uterus reported in endometriosis [3,4]. It is known that TNF, via its membrane receptors, may activates several processes leading to the activation of AP1 and $\mathrm{NF} \kappa \mathrm{B}$ transcription factors, which implicate the induction of several target genes involved in cell proliferation, inflammation and cell death in many tissues $[20,22]$. We previously reported the augmented $\mathrm{NF} \kappa \mathrm{B}$ binding to $\kappa \mathrm{B}$ DNA sequence in the target genes in control endometria, and on the contrary, the reduced binding in eutopic endometria from women with endometriosis during the late secretory phase [20]. These results are in agreement with the increase TNFR1 protein expression in control endometria and the decrease in endometriosis endometria found in the present study, indicating an aberrant function of the TNF system, which may be involved in the low apoptosis rates observed at this stage of the menstrual cycle in this pathology.

The high expression of the mRNA and protein of TNFR1 and the low expression of TNFR2, in agreement to Kharfi et al. (2003) [23] in eutopic endometrium from endometriosis suggest that the TNFR1 pathway might predominantly mediate the TNF response through paracrine or autocrine signalling, with the TNFR2 action potentially limited to immune system. Furthermore, it has been reported that membrane-bound TNF rather than soluble TNF activates TNFR2, so its physiological role could be underestimated $[14,24,25]$. At this respect, we cannot ruled out the probably peptide degradation during tissue storage when comparing the weak TNF concentration in endometrial explant homogenates with the strong TNF brown staining in the immediately formaldehydefixed tissue used for immunohistochemistry.

Although TNFR1 and sTNFR1 presented similar patterns throughout the menstrual cycle, the differences observed in endometriosis compared to control endometria could be a consequence of the receptor cleavage in vivo, which may contribute to the low concentration found during the late secretory phase and the elevated concentration reported in the peritoneal fluid [18].

Because a fine immune balance leads to reproductive success, the immune response alterations promote the ectopic growth and survival of the endometrium [26] and in addition, are related to the low pregnancy rates reported in endometriosis patients [27,28], our results support a dysregulation on the TNF action in this disease. Furthermore, the location and the low percentage of CD45-positive endometrial stromal cells in both groups of patients indicate that TNF and TNFR1 are mainly synthesized by endometrial cells and in contrast, TNFR2 by infiltrating leukocytes, whose identification is required. Besides, no differences were found in the CD45positive infiltrating leukocytes percentage between control and endometriosis samples, albeit an elevated macrophage number has been reported using the specific CD68-PGM antibody in eutopic endometria from endometriosis $[29,30]$.

Distal effects through the agonistic or antagonistic activities of sTNFR, which acts as a TNF-carrier by modifying its half-life or a binding protein or a decoy receptor that down-regulates its signaling pathway, may lead to physiological or pathological responses [31,32]. The appearance of sTNFR in the plasma or other fluids in several chronic inflammatory disorders may have a protective role, neutralizing TNF bioactivity to prevent its adverse pathological actions $[18,33,34]$. Even more, the pharmacological use of a soluble form of TNFR1 in animal model of endometriosis reduced the lesion area and induced disease regression $[35,36]$, indicating its potential clinical use.

In summary, this study establishes that the expression of TNF and TNFR1 and the concentration of the STNFR1 and sTNFR2 in eutopic endometrium from women with and without endometriosis are dependent on the menstrual cycle. The differences on the protein expression pattern and the concentration of TNFR1 and sTNFR1 between both groups, mainly during the mid and late secretory phases, may play a role in the mechanisms responsible from the lower implantation rates observed in women with endometriosis. Furthermore, this phenomenon could be related to the altered cell death, which favors the augmented cell viability in eutopic and ectopic endometria. The later is seen as one of the main factors favoring ectopic endometrial implantation and growth outside the uterus.

\section{ACKNOWLEDGEMENTS}

The authors are grateful to the women who donated tissue, as without their generous contributions, this study would not have been possible. This work was supported by Fondo Nacional de Ciencias y Tecnología 
(FONDECYT) \#1080229 and \#1120074, and the Re-Entry Grant PLACIRH Pre-Pro005/2003, Santiago, Chile.

\section{REFERENCES}

[1] Roberts, M., Luo, X. and Chegini, N. (2005) Differential regulation of interleukins IL-13 and IL-15 by ovarian steroids, TNF- $\alpha$ and TGF- $\beta$ in human endometrial epithelial and stromal cells. Molecular Human Reproduction, 11, 751-760.

[2] Giudice, L.C. and Kao, L.C. (2004) Endometriosis. Lancet, 364, 1789-1799. doi:10.1016/S0140-6736(04)17403-5

[3] Meresman, G.F., Vighi, S., Buquet, R.A., Contreras-Ortiz, O., Tesone, M. and Rumi, L.S. (2000) Apoptosis and expression of $\mathrm{Bcl}-2$ and $\mathrm{Bax}$ in eutopic endometrium from women with endometriosis. Fertility \& Sterility, 74, 760766. doi:10.1016/S0015-0282(00)01522-3

[4] Johnson, M.C., Torres, M., Alves, A., Bacallao, K., Fuentes, A., Vega, M., et al. (2005) Augmented cell survival in eutopic endometrium from women with endometriosis: Expression of c-myc, TGF-betal and bax genes. Reproductive Biology Endocrinology, 3, 45-52. doi:10.1186/1477-7827-3-45

[5] Kyama, C.M., Debrock, S., Mwenda, J.M. and D'Hooghe, T.M. (2003) Potential involvement of the immune system in the development of endometriosis. Reproductive Biology and Endocrinology, 1, 123. doi:10.1186/1477-7827-1-123

[6] Yamauchi, N., Harada, T., Taniguchi, F., Yoshida, S., Iwabe, T. and Terakawa, N. (2004) Tumor necrosis factor-alpha induced the release of interleukin- 6 from endometriotic stromal cells by the nuclear factor-kappaB and mitogen-activated protein kinase pathways. Fertility \& Sterility, 82, 1023-1028.

doi:10.1016/i.fertnstert.2004.02.134

[7] Haider, S. and Knofler, M. (2009) Human tumor nerosis factor: Physiological and pathological roles in placenta and endometrium. Placenta, 30, 111-123. doi:10.1016/j.placenta.2008.10.012

[8] Hunt, J.S., Chen, H.L. and Miller, L. (1996) Tumor necrosis factors: Pivotal components of pregnancy. Biology of Reproduction, 54, 554-562. doi:10.1095/biolreprod54.3.554

[9] Tabibzadeh, S., Satyaswaroop, P.G., von Wolff, M. and Strwitzki, T. (1999) Regulation of TNF- $\alpha$ mRNA expression in endometrial cells by TNF- $\alpha$ and by oestradiol withdrawal. Molecular Human Reproduction, 5, 11411149. doi:10.1093/molehr/5.12.1141

[10] Von Wolff, M., Thaler, C.J., Strowitzki, T., Broome, J., Stolz, W. and Tabibzadeh, S. (2000) Regulated expression of cytokines in human endometrium throughout the menstrual cycle: Dysregulation in habitual abort. Molecular Human Reproduction, 6, 627-634. doi:10.1093/molehr/6.7.627

[11] Mohan, M.J., Seaton, T., Mitchell, J., Howe, A., Blackburn, K., Burkhart, W., et al. (2002) The tumor necrosis factor-alpha converting enzyme (ADAM17): A unique metalloproteinase with highly defined substrate selectivity. Biochemistry, 41, 9462-9469. doi:10.1021/bi0260132

[12] Zheng, Y., Saftig, P., Hartmann, D. and Blobel, C. (2004) Evaluation of the contribution of different ADAMs to tumor necrosis factor $\alpha$ (TNF $\alpha$ ) shedding and of the function of the TNFalpha ectodomain in ensuring selective stimulated shedding by the TNF $\alpha$ convertase (ADAM17/ ADAM17). Journal of Biological Chemistry, 279, 4289842906. doi:10.1074/jbc.M403193200

[13] Brockhaus, M., Schoenfeld, H.J., Schlaeger, E.J., Hunziker, W., Lesslauer, W. and Loetscher, H. (1990) Identification of two types of tumor necrosis factor receptors on human cell lines by monoclonal antibodies. Proceedings of the National Academy of Sciences of the United States of America, 87, 3127-3131. doi:10.1073/pnas.87.8.3127

[14] Grell, M., Douni, E., Wajant, H., Lohden, M., Clauss, M., Maxeiner, B., et al. (1995) The transmembrane form of tumor necrosis factor is the prime activating ligand of the $80 \mathrm{kDa}$ tumor necrosis factor receptor. Cell, 83, 793-802. doi:10.1016/0092-8674(95)90192-2

[15] Higuchi, M. and Aggarwal, B.B. (1994) TNF induces internalization of the p60 receptor and shedding of the p80 receptor. Journal of Immunology, 152, 3550-3558.

[16] Hunt, J.S., Chen, H.L., Hu, X.L. and Tabibzadeh, S. (1992) Tumor necrosis factor-alpha messenger ribonucleic acid and protein in human endometrium. Biology of Reproduction, 47, 141-147. doi:10.1095/biolreprod47.1.141

[17] von Wolff, M., Classen-Linke, I., Heid, D., Krusche, C.A., Beier-Hellwig, K., Karl, C., et al. (1999) Tumor necrosis factor-alpha (TNF-alpha) in human endometrium and uterine secretion: An evaluation by immunohistochemistry, ELISA and semiquantitative RT-PCR. Molecular Human Reproduction, 5, 146-152. doi:10.1093/molehr/5.2.146

[18] Koga, K., Osuga, Y., Tsutsumi, O., Okagaki, R., Momoeda, M., Yano, T., et al. (2000) Increased concentrations of soluble tumor necrosis factor receptor (sTNFR) I and II in peritoneal fluid from women with endometriosis. Molecular Human Reproduction, 6, 929-933. doi:10.1093/molehr/6.10.929

[19] Pino, M., Galleguillos, C., Torres, M., Sovino, H., Fuentes, A., Boric, M.A., et al. (2009) Association between MMP1 and MMP9 activities and ICAM1 cleavage induced by TNF in stromal cell cultures from eutopic endometria of women with endometriosis. Reproduction, 138, 837-847. doi:10.1530/REP-09-0196

[20] Ponce, C., Torres, M., Galleguillos, C., Sovino, H., Boric, M.A., Fuentes, A., et al. (2009) Nuclear factor kappaB pathway and interleukin- 6 are affected in eutopic endometrium of women with endometriosis. Reproduction, 137, 727-737.

[21] Jokhi, P.P., King, A. and Loke, Y.W. (1994) Cytokine production and cytokine receptor expression by cells of the human first trimester placental-uterine interface. $C y$ tokine, 9, 126-137. doi:10.1006/cyto.1996.0146

[22] Otterson, M.F., Nie, L., Schmidt, J.L., Link, B. J., Jovanovic, N., Lyros, O., et al. (2012) EUK-207 protects hu- 
man intestinal microvascular endothelial cells (HIMEC) against irradiation-induced apoptosis through the $\mathrm{Bcl} 2$ pathway. Life Sciences, 91, 771-782. doi:10.1016/j.1fs.2012.08.018

[23] Kharfi, A., Labelle, Y., Mailloux, J. and Akoum, A. (2003) Deficient expression of tumor necrosis factor receptor type 2 in the endometrium of women with endometriosis. American Journal of Reproductive Immunology, 50, 33-40. doi:10.1016/j.cyto.2009.11.022

[24] Tartaglia, L.A., Pennica, D. and Goeddel, D.V. (1993) Ligand passing: The 75-kDa tumor necrosis factor (TNF) receptor recruits TNF for signalling by the $55-\mathrm{kDa} \mathrm{TNF}$ receptor. The Journal of Biological Chemistry, 268, 1854218548.

[25] Shibata, H., Abe, Y., Yoshioka Y., Nomura, T., Sato, M., Kayamuro, H., et al. (2010) Generation of mouse macrophages expressing membrane-bound TNF variants with selectivity for TNFR1 or TNFR2. Cytokine, 50. 75-83.

[26] Herington, J.L., Bruner-Tran, K.L., Lucas, J.A. and Osteen, K.O. (2011) Immune interactions in endometriosis. Expert Review of Clinical Immunology, 7, 611-626. doi:10.1586/eci.11.53

[27] Gupta, S., Goldberg, J.M., Aziz, N., Goldberg, E., Krajcir, N. and Agarwal, A. (2008) Pathogenic mechanisms in endometriosis-associated infertility. Fertility and Sterility, 90, 247-257. doi:10.1016/j.fertnstert.2008.02.093

[28] Tremellen, K.P. and Russell, P. (2012) The distribution of immune cells and macrophages in the endometrium of women with recurrent reproductive failure. II: Adenomyosis and macrophages. Journal Reproductive Immunology, 93, 58-63. doi:10.1016/j.jri.2011.12.001

[29] Khan, K.N., Masuzaki, H., Fujishita, A., Kitajima, M., Sekine, I. and Ishimaru, T. (2004) Differential macrophage infiltration in early and advanced endometriosis and adjacent peritoneum. Fertility and Sterility, 81, 652661. doi:10.1016/j.fertnstert.2003.07.037

[30] Berbic, M., Schulke, L., Markham, R., Tokushige, N., Russell, P. and Fraser, I.S. (2009) Macrophage expression in endometrium of women with and without endometrio- sis. Human Reproduction, 24, 325-332. doi:10.1093/humrep/den393

[31] Aderka, D., Engelmann, H., Maor, Y., Brakebusch, C. and Wallach, D. (1992) Stabilization of the bioactivity of tumor necrosis factor by its soluble receptors. Journal Experimental Medicine, 175, 323-329. doi:10.1084/jem.175.2.323

[32] Rojas-Cartagena, C., Appleyard, C.B., Santiago, O.I. and Flores, I. (2005) Experimental intestinal endometriosis is characterized by increased levels of soluble TNFR2 and downregulation of TNFR1 and TNFR2 gene expression. Biology of Reproduction, 73, 1211-1218. doi:10.1095/biolreprod.105.044131

[33] Van Zee, K.J., Kohno, T., Fischer, E., Rock, C.S., Moldawer, L.L. and Lowry, S.F. (1992) Tumor necrosis factor soluble receptors circulate during experimental and clinical inflammation and can protect against excessive tumor necrosis factor alpha in vitro and in vivo. Proceedings of the National Academy of Sciences of the United States of America, 89, 4845-4849. doi:10.1073/pnas.89.11.4845

[34] Backonja, M.M., Coe, C.L., Muller, D.A. and Schell, K. (2008) Altered cytokine levels in the blood and cerebrospinal fluid of chronic pain patients. Journal Neuroimmunology, 195, 157-163. doi:10.1016/j.jneuroim.2008.01.005

[35] Altan, Z.M., Denis, D., Kagan, D., Grund, E.M., Palmer, S.S. and Nataraja, S.G. (2010) A long-acting tumor necrosis factor $\alpha$-binding protein demonstrates activity in both in vitro and in vivo models of endometriosis. Journal of Pharmacology and Experimental Therapeutics, 334 460-466. doi:10.1124/jpet.110.166488

[36] D’Hooghe, T.M., Nugent, N.P., Cuneo, S., Chai, D.C., Deer, F., Debrock, S., et al., (2006) Recombinant human TNFR1 (r-hTBP1) inhibits the development of endometriosis in baboons: a prospective, randomized, placebo and drug-controlled study. Biology of Reproduction, 74, $131-136$ 